\title{
Complementary and Alternative Medicine Provider Knowledge Discourse on Holistic Health
}

\author{
Vinita Agarwal * \\ Department of Communication Arts, Salisbury University, Salisbury, MD, United States
}

OPEN ACCESS

Edited by:

Iccha Basnyat,

National University of Singapore,

Singapore

Reviewed by:

Dyah Pitaloka,

University of Sydney, Australia

Marissa Joanna Doshi,

Hope College, United States

*Correspondence: Vinita Agarwal vxagarwal@salisbury.edu

Specialty section:

This article was submitted to Health Communication,

a section of the journal Frontiers in Communication

Received: 06 November 2017 Accepted: 26 March 2018

Published: 12 April 2018

Citation:

Agarwal V (2018) Complementary and Alternative Medicine Provider Knowledge Discourse on Holistic

Health. Front. Commun. 3:15. doi: 10.3389/fcomm.2018.00015
Complementary and alternative medicine (CAM) promises a wide array of therapies employed increasingly by consumers for disease prevention and health promotion. Despite this increasing use, however, CAM and biomedical paradigms are often not combined effectively in the US. The lack of coordination negatively impacts several aspects of patient care including CAM and biomedical provider-patient relationships and the practice of integrative medicine (IM). The goal of this study is to understand how CAM providers position their knowledge and practice of holistic health within the healthcare landscape in the US. In-depth interviews with CAM providers ( $N=17)$ sampled from practices in the mid-Atlantic region of the US were analyzed for provider descriptions of holistic health. Discourse analysis of CAM provider interviews identifies the three themes employed by CAM providers to describe holistic health as comprising the: (a) epistemologies of legitimization and identity, (b) epistemologies of sense and intuition, and (c) epistemologies of environment and community. The three epistemologies define holistic health by organizing diverse knowledge foundations through reconciling and integrating differences, including diverse modes of evidence such as non-empirical forms of whole body experiences, and privileging the relational praxis through integrating the individual's biological and sociocultural environment. The epistemologies illuminate how CAM knowledge and practice is positioned as alternative within the sociocultural context of the participants and reflect CAM providers' challenges in carving out a distinct knowledge space reflecting their professional identity. CAM providers' discourse encompasses the ontological and experiential-relational praxis to foreground health as a mutually constitutive, ongoing process of granting legitimacy to diverse sense-making ontologies of medicine within a continuum of provider-patient meaning-making. Theoretically, CAM knowledge of holistic health integrates the experiential praxis of the patient's spiritual and physiological self and the relational praxis of the patient's biological-sociocultural-epigenetic relationships in the conceptualization and delivery of health outcomes. The study findings recommend including CAM knowledge discourses to inform the epistemological foundations of basic medicine. Pragmatically, the study recommends support for efforts to include credentialing of CAM practitioner teaching within allopathic healthcare institutions, faculty development within existing allopathic health professional schools, and incorporation of CAM content in allopathic medical education and practice.

Keywords: knowledge discourses, complementary and alternative medicine (CAM) providers, mid-Atlantic region of the United States, discourse analysis, biomedicine, medical education, holistic health, practitioners 


\section{INTRODUCTION}

Complementary and alternative medicine (CAM) promises a wide array of therapies that are increasingly used by consumers for disease prevention and health promotion. In low- to middleincome countries, about $80 \%$ of the population may rely on CAM to meet primary healthcare needs (World Health Organization, 2004). In the US, an estimated 4 in 10 adults use some form of CAM care (National Center for Complementary Integrative Health, 2017b). The increasing use of CAM underscores the need for informed representation of CAM and guidelines that attend to their diverse cultural traditions (Dutta, 2007; Sharf et al., 2012). Although CAM use has increased with patients taking a more proactive role in their own health, these two paradigms are often not combined effectively. The goal of this study is to understand how CAM providers in the US position their knowledge and practice of holistic health. This examination of CAM provider discourse contributes by explicating the epistemological foundations of holistic health defining CAM's knowledge field, modes of validating evidence, and the relational praxis as a continuum between the biological-socioculturalepigenetic environment.

Despite evidence that patients want a physician open to listening to their CAM healthcare experiences (Jong et al., 2012), several constraints hamper successful coordination of care between CAM and biomedical systems. These include sociocultural barriers (Foote-Ardah, 2004), patient anxiety (Broom and Tovey, 2008), physician preferences (Shelley et al., 2009), and patient-physician communication regarding CAM use (Agarwal, 2018). The lack of patient disclosure of CAM use can compromise the safety and efficacy of care and increase the possibility of adverse interactions (Hsiao et al., 2006). The challenge of coordinating care across healthcare paradigms underscores the need to define CAM philosophies on their own terms. Furthermore, CAM knowledge and practices have been discussed largely in relation with those of conventional biomedicine (e.g., Barrett et al., 2003; Ramadurai et al., 2016). These barriers become more significant as integrative medicine (IM) seeks to envision equitable representations of medical knowledge and healthcare practices. Thus, there is a need for further research to explicate how CAM providers' discourse positions holistic health in the US healthcare landscape to achieve the goals of IM (Bann et al., 2010; Agarwal, 2017).

The present examination centers CAM provider discourse to critique the positioning of diverse knowledges in medicine in several ways. First, in foregrounding CAM providers' critique of their own and allopathic medicine, the study draws attention to the complex power relations, inclusionary and exclusionary strategies, and interprofessional tensions between biomedical and CAM knowledge systems (Ahn et al., 2006). Second, by foregrounding CAM provider discourses, the study extends theoretical understandings of patient-provider communication beyond biomedical perspectives on CAM paradigms (Chatwin, 2012). Third, foregrounding CAM provider discourses provides greater understandings of patient empowerment in chronic care domains. Fourth, by employing qualitative methodologies, the study captures the conceptual complexity of CAM ontologies in ways that are challenging to achieve through probabilistic approaches (Cochrane and Possamai-Inesedy, 2013). The next section lays out the ontological perspectives as they inform discourses of allopathic and CAM models of care.

\section{KNOWLEDGE DISCOURSES OF TRADITIONAL AND CAM SYSTEMS}

CAM is a categorical label that subsumes a range of therapeutic modalities like yoga, tai chi, qi gong, and chiropractic care. In defining their holistic philosophy, CAM modalities draw upon their deep historical trajectory; rich local, culturallysituated practices; and complex indigenous belief-systems. CAM providers' belief system is reflected in the materiality of their practice through relational, structural, and philosophical pathways (Agarwal, 2018). However, this diversity of knowledge bases makes the CAM model of care prone to being mischaracterized, particularly as CAM interventions are complex constructions of socioculturally-based healing philosophies (Caspi et al., 2003). For example, Ayurveda as a belief system reflects a way of life and as a healing philosophy subsumes a range of practices from spiritual music to chanting and nutrition. Thus, ethical justification strategies critiquing the use of CAM need to also examine its epistemological, axiological, and ontological differences with biomedicine (Mertz, 2007).

Moreover, CAM and allopathic providers employ seemingly contradictory discourses to make legitimacy claims (Hirschkorn, 2006). The intrinsically and ontologically connected nature of CAM suggests that complex non-hierarchical, cyclical, and adaptive whole systems approaches are better positioned to capture the mechanisms of CAM interventions (Verhoef et al., 2005). Yet, a review of the representation of CAM in traditional science publications suggests a bias toward probabilistic and experimental methodologies (Caulfield and DeBow, 2005). At the same time, others have drawn attention to a shift away from effectiveness research in CAM journals suggesting a confusion regarding its assumptions and principles (Coelho et al., 2007). In sum, a review of biomedical research suggests a lack of direction for a clear operational identity for CAM, generating negative stereotypes, prejudices, and misconceptions among physicians (Willard, 2005; Hsieh et al., 2016; Roth et al., 2017). A lack of consensus regarding the philosophical foundations of holistic paradigms minimizes their contributions and foregrounds the need to justify the methodological premises of both models of care for their integration.

The enduring challenge of reconciling CAM and biomedical ontological approaches highlights process and ideological barriers that undermine the integrity of different domains (Mizrachi et al., 2005; Jagtenberg et al., 2006). Some scholars argue that CAM providers' knowledge and practice should inform how the CAM and biomedical models are integrated in patient care, while others suggest that patients should be the frame of reference. Such deliberations further complicate understandings of the structure and practice 
of IM (Caspi et al., 2003; Appendix 1 in Supplementary Material). The goal of patient-centered care adhering to holistic principles and emphasizing clinical expertise can be furthered through informed critiques of both CAM and allopathic philosophies (Ooi et al., 2016). Successful integration of these goals implies understanding the distinct ideological bases of allopathic and traditional knowledge philosophies.

Insufficient knowledge of CAM ontologies and practices alongside a lack of institutional support poses a barrier toward effective integration (Jain and Astin, 2001). This gap has negative implications for coordination across the healthcare spectrum. Key concerns among CAM educators from the Delphi process highlighted the need to integrate CAM resources institutionally in the allopathic patient-provider relationship (Benjamin et al., 2007) ${ }^{1}$. Biomedical practitioners enact differing patterns of exclusionary closure, such as by dominating patient charting and diagnostic tests. CAM practitioners assert control by performing their own patterns of exclusionary closure (e.g., appropriating biomedical language), increasing their professional status by working with biomedicine, and by "breaking boundaries" (Almeida, 2016; Agarwal, 2018). Aligning diverse knowledge bases in the practice of medicine is important because providers shape patient beliefs and decision-making based on their training (Yang et al., 2017). Thus, a lack of clarity in ontological frameworks negatively impacts inter-professional collaboration and the patient relationship.

Illuminating the assumptions of biomedicine helps enhance equitable and informed integration of care consistent with ethical principles of medical pluralism to support equitable knowledge representation (Tilburt and Miller, 2007; Kantor, 2009). Effective knowledge representation between diverse approaches can benefit patients through the provision of improved and broad forms of integrative care (Hollenberg, 2006). This is important because despite a move to gather evidencebased findings demonstrating CAM benefits in identified priority areas (National Center for Complementary Integrative Health, 2017a), patients continue to use CAM therapies to supplement or advance their treatment goals in those and multiple other domains (e.g., Helyer et al., 2006; Wanchai et al., 2010).

The research question posed by the study asks: How does CAM providers' discourse of holistic health define CAM knowledge relations?

\footnotetext{
${ }^{1}$ The representatives from the Academic Consortium for Complementary and Alternative Health Care (ACCAHC) and the Oregon Collaborative for Complementary and Integrative Medicine (OCCIM) came together in a task force to participate in a Delphi process for greater collaboration between conventional medical schools and CAM academic institutions in developing IM curricula. This task group used an internet-based survey of all 30 conventional medicine programs that incorporate integrative medicine and 130 federallyrecognized CAM programs in chiropractic, naturopathic medicine, acupuncture, and Oriental medicine, massage therapy, and direct-entry midwifery to explore shared responses (ACCAHC/OCCIM Task Force).
}

\section{METHODS}

\section{Participants and Procedures Participants}

This study was reviewed and approved by the Institutional Review Board (IRB) of the Salisbury University, Maryland USA. Participants were provided and read a copy of informed consent and consent was recorded on tape. This consent procedure was approved by the IRB of the Salisbury University, Maryland USA. Obtaining a separate written informed consent was not a requirement as per the IRB that approved the study. Data was gathered through indepth, semi-structured qualitative interviews $(N=18$, total interview duration: $31 \mathrm{~h}$ and $33 \mathrm{~s}$; Table 1) with CAM providers purposively sampled from practices located in the mid-Atlantic region of the United States. Participants ( $N=18, M=8, F=10)$ encompassed a range of modalities $($ Yoga $=4$, Acupuncture $=4$, Chiropractic $=5$, Reiki $=3$, Massage therapist $=2$, Hypnotherapist $=1$; average age $=50$ years; Table 1). Due to a recording glitch, one participant's interview could not be accessed, thus the study includes transcripts from 17 participants (i.e., $N=17$ for the study).

\section{Sampling}

CAM providers comprising a range of modalities, who were either working with a CAM practice or independently managing their practice were purposively sampled for the study. As most CAM professionals tend to employ more than one modality, the study invited participants to focus on the modality that constituted the core of their practice. For example, if a chiropractor also employed mindfulness, then the main holistic health discourse focused on their thoughts on their field of chiropractic, and where needed, how mindfulness enhanced their particular practice.

A non-probabilistic, purposive sampling approach employing the criterion of maximum variability was used (Table 1 ). This method allows for the identification and selection of individuals who are the most knowledgeable about, or experienced with, the phenomenon of interest and able to communicate in a reflective manner (for maximizing validity and for effective study resource management; Patton, 2002; Cresswell and Plano Clark, 2011). Likewise, the criterion of maximum validity allowed the researcher to include a range of views from different modalities to document unique or diverse variations in the sample and identify common patterns underlying variations in the study domains. Upon completion of each interview, the audio recordings were reviewed to gain an understanding of how the concepts were elucidated. The process of reviewing and recruiting was continued until it was perceived that similar responses were being obtained for the core concepts (Strauss and Corbin, 1998). Once the researcher felt that saturation was reached (Miles and Huberman, 1994), further recruitment was stopped and the process of data preparation for analysis was initiated. 
TABLE 1 | Participant characteristics.

\begin{tabular}{|c|c|c|c|c|c|}
\hline$\#$ & Name, gender & Age (years) & Experience $^{\Lambda}$ & Education & Race/Marital status*/Religious beliefs \\
\hline 1 & Alice, F & 58 & 0,10 years & $\begin{array}{l}\text { Community College, Massage } \\
\text { certification }\end{array}$ & White/M/Christian \\
\hline 2 & Halen, M & 23 & O, 2 years & $\begin{array}{l}\text { Some college, Bikram Teacher } \\
\text { Training }\end{array}$ & Jewish/S/No beliefs \\
\hline 3 & Carly, F & 63 & 0,10 years & Masters, Oriental Medicine & White/W/Buddhist \\
\hline 4 & Madison, F & 39 & O, about 10 years & College & Armenian-Irish-German/D/Spiritual \\
\hline 5 & Bob, M & 63 & $P, 31$ years & Two masters degrees & Asian-Caucasian/D/No religious affiliation \\
\hline 6 & Max, M & 59 & $P, 42$ years, $O$ & Some college & White/M /No religious affiliation \\
\hline 7 & Phillip, M & 56 & O & Doctor of Chiropractic & White/S/No religious affiliation \\
\hline 8 & Harry, M & 61 & $P, 36$ years, $O$ & Doctor of Chiropractic & White/M/Presbyterian \\
\hline 9 & Alexis, F & 40's & $P, 16$ years, $O$ & Doctor of Chiropractic & White/M/Christian \\
\hline 10 & Karl, M & 43 & $\mathrm{P}, \mathrm{O}$ & Doctor of Chiropractic & White/M/Methodist \\
\hline 11 & Ellie, F & N/A & $\begin{array}{l}\text { Recording glitch, unable to } \\
\text { transcribe }\end{array}$ & Doctor of Chiropractic & White/M/no religious affiliation \\
\hline 12 & Charles, M & 32 & 5 years, 0 & Masters, Acupuncture & White/S/Spiritual \\
\hline 13 & Catherine, F & 63 & $\mathrm{O}$ & Reiki, some college & White/M/Episcopalian \\
\hline 14 & Amy, F & 51 & Part of a practice, $4-5$ years & $\begin{array}{l}\text { Orthobionomy, student: MA, } \\
\text { Education Technology }\end{array}$ & White/M/No religious affiliation \\
\hline 15 & Ana, F & 56 & 8 years, part of a practice & Reiki master, hypnotherapy & White/M/Spiritual \\
\hline 16 & Dick, M & Mid-40's & 0,25 years & Yoga instructor, college education & White/M/Spiritual \\
\hline 17 & Abby, F & 55 & 37 years, studios & High school & White/S/Spiritual \\
\hline 18 & Brianna, F & $40-45$ & $\mathrm{~N} / \mathrm{A}$ & $\begin{array}{l}\text { Reiki, Bachelor of psychology, } \\
\text { certified, hypnotherapy }\end{array}$ & Hispanic/M/Spiritual \\
\hline
\end{tabular}

${ }^{\Lambda} \mathrm{O}$, Own studio; P, Practitioner. ${ }^{\star} M$, married; $S$, single; $D$, divorced; $W$, widowed.

\section{Data Gathering and Analysis Data Gathering}

The interview guide was designed to probe core domains of the study in depth (see Appendix 2 in Supplementary Material for domains). Interviews ranged from $48 \mathrm{~min}$ and $53 \mathrm{~s}$ to $2 \mathrm{~h}, 16 \mathrm{~min}, 23 \mathrm{~s}$, with an average interview duration of $2 \mathrm{~h}$ and $12 \mathrm{~m}$. Interviews were conducted in-person by the researcher and audio-recorded at the participants' practices and in public venues (e.g., chiropractic centers, acupuncture clinics). Verbatim transcription by a professional transcriptionist agency yielded a total interview data of 1,272 doublespaced pages. Upon transcription, the researcher spot-checked random sections of the completed transcripts against the audio recordings for accuracy, and assigned pseudonyms to preserve confidentiality (see Agarwal, 2018 for complete data information).

\section{Data Analysis}

Discourse analysis was employed to understand how the concept of holistic health was constituted in relationship with the institution(s), social structure(s), and the CAM providers' practice and beliefs. Discourse analysis recognizes that practices (e.g., how holistic health is represented by CAM providers) are ideological and have material effects.

Because language informs meaning making, poststructuralist analyses of knowledge discourses are well-suited for revealing struggles between diverse medical approaches as these influence the legitimization of particular paradigms. In poststructuralist thought, knowledge is discursively constituted through language and other signifying practices situated within particular historical-sociocultural discourses (Foucault, 1972; Schreiber, 2005). Thus, these discourses support and perpetuate existing power relations and have particular material implications for the subjects being constituted (Fairclough and Wodak, 1997).

Discourse analysis has been employed in healthcare research to understand provider practices and patient perspectives in complex and contested situations (Ho et al., 2015; Scott and Caughlin, 2015). The researcher sought to be aware of negotiations of power (e.g., between different models of care) and negotiation of differences (e.g., between CAM providers, between CAM and biomedical providers, or between CAM providers and their clients). In this examination of how holistic health was elucidated by CAM providers, the researcher directed her gaze not only toward the description and explanation of holistic health, but also toward revealing how empowerment and agency were constituted in participant discourse. The researcher sought to maintain self-reflexivity through being mindful of the ways in which "the researcher's past experiences, points of view, and roles impact [the] researcher's interactions with, and interpretations of the research scene" (Tracy, 2013, p. 2). Being mindful of the positionality of the researcher as an instrument for registering observations, noting participant gestures, constituting the interview space along with the participant, and engaging in interpretation (Tracy, 2013), the researcher sought to make her positionality explicit to the participants. To do so, the researcher 
explained her formal (through certifications) and informal (as a native cultural participant) knowledge of holistic philosophies from an Ayurvedic perspective, and acknowledged this explicitly to the participants in the research process (Tracy, 2013). The researcher recognized the participants' recruitment criteria as a provider, and hence, their positionality as a recognized (i.e., expert) professional in their field. Similarly, at the start of the interview process, the researcher sought to make explicit the goal of the study to understand knowledge forms in all its diversity (Fairclough, 1995).

The researcher engaged in a line-by-line examination of the textual transcripts to examine CAM providers' discourse on holistic health and practices. In doing so, the researcher looked for instances of CAM providers' descriptions and explanations of the concepts of holistic, healing, and health in the different contexts explored in the study (e.g., in the providers' life, with respect to their religious beliefs, worldview, inter-, and intra-professional interaction with other CAM providers or biomedical providers), and an understanding of their own knowledge independently and in relationship with other models. The researcher looked for instances to illustrate (e.g., confirm or disconfirm, align with, challenge, or represent their knowledge) how the discourse served sustain, reproduce, or transform the status quo from the standpoint of CAM providers' perceived positionality. The researcher examined how CAM providers describe their role, interactions, upbringing, relationships (with family, clients, biomedical, and CAM providers of similar or different modalities), beliefs, and their CAM practice (as constitutive of their sense of self and approach to health and healing).

In the readings, the researcher first identified in vivo codes (descriptions of holistic healing and its relationships with various concepts; Strauss and Corbin, 1998). The researcher then sought to draw out relationships among these codes through a process of constant comparison to collapse and further refine them (axial coding). Third, the researcher went through the axial codes to draw out their underlying abstract concepts and relationships they referenced (selective coding; Strauss and Corbin, 1998). This process was repeated several times, each time to refine the codes further and deepen the analysis. Through this iterative process, the research question was also refined. Thus, for example, as the analysis delved deeper on the principles underlying the practitioner's knowledge and practice, the researcher began to sharpen the focus on CAM providers' epistemological position, thus ultimately revising the research question in nuanced ways (e.g., from how CAM providers redefine knowledge to how they define knowledge).

\section{Findings}

The findings illuminate how CAM providers' discourse on holistic health defines CAM knowledge relations through the three epistemologies of (a) legitimization and identity, (b) sense and intuition, and (c) environment and community (Table 2). The epistemologies provide a framework representing how knowledge is constructed by CAM providers in practice and contribute to greater theoretical and pragmatic understandings of IM and CAM models of care.

\section{Epistemologies of Legitimization and Identity}

CAM providers' discourse employed epistemologies of legitimization and identity to represent tensions between, and draw parallels with practice in ways that sustain, limit, or contest differences in knowledge forms (Table 2). In their discourse, CAM providers represent knowledge through the lens of their actions (i.e., ability to care for their patients) and outcomes (i.e., how they define holistic health) to legitimize their identity.

By highlighting differences, CAM providers' discourse described how they positioned their CAM modality as science. Amy, an orthobionomist, described how her clients' assumptions of normative healthcare processes positioned her practice as alternative, even though they found it effective: "I'd talk to them about why I'm working on their leg. And, when they notice, when they get up, [that] there's a difference, they're happy with that." Yet, Amy was aware of the skepticism of her patients: "I've worked on people who've been given gift certificates and they're uncomfortable with touch [as a healing instrument], so... the massage is not going to work for them." Even when she was effective in helping her patients heal, she faced skepticism: "I've heard the stories...you're doing witchy stuff, or you're doing magical stuff."

Amy thus aligned her practice with science, saying: "it is science and I'm not hurting you, it's just a matter of, or, even an electromagnet, like it's a field of force, and, so yes, it can affect how they respond to massage." Yet Amy herself struggled to accept the efficacy of her practice as science: "their whole worldview is... especially if they start feeling, like a tingling-'what're you doing to me?' And it's hard to say it's really science." This enduring tension illuminates Amy's struggle to simultaneously

TABLE 2 | CAM provider knowledge discourse of holistic health.

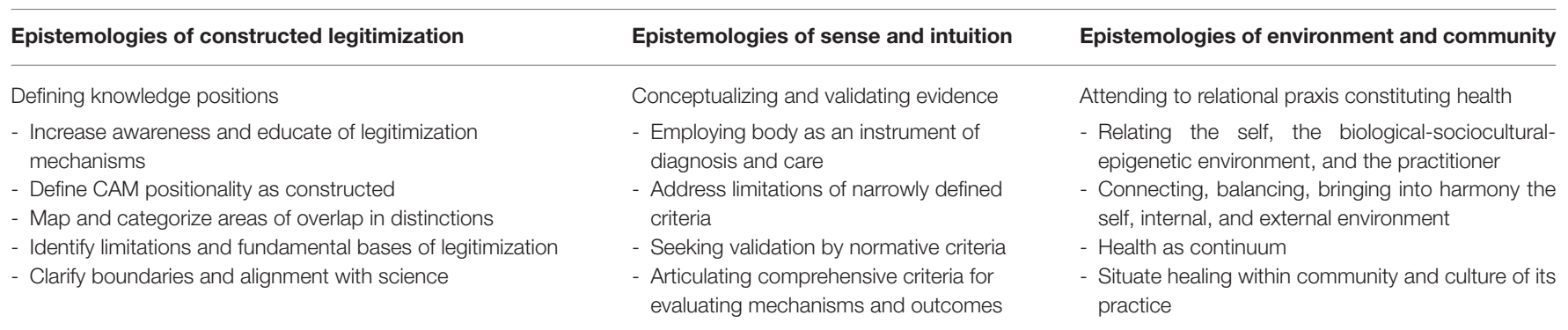


contest and align with scientific discourse in her clients' eyes. Pragmatically, to bolster the legitimacy of her own practice for clients and regulatory agencies, Amy sought to: "make sure that I've taken enough credits."

Bob, an acupuncturist, described holistic health as connected and preventive, as "flourishing, where you are being the best you can be...And our spiritual connectedness is a very important part of it too." Bob contested the current approach that "exists in the current medical system, and exists in the street too," whereby "no one is taught to think about prevention," and believed that "we don't learn well in medical school." For Bob, situating his practice in the healthcare continuum meant identifying and carving out a space for CAM in preventive medicine. However, Bob saw himself as treating his patients too: "most people who come to see me are already dealing with some kind of symptoms." For Bob, everything was: "connected to everything... your values, your aspirations, your spiritual outlook...it is like one integrated system. So... it is really not just the body that we are taking care of, but just the whole." Bob's discourse highlighted how the goal of healing the whole body competed with the healthcare practice: "IM... is based [on the] hospital administration's goals, which are based on [the] current biomedical method. So there is... some contradiction because... hospitals need to [m]ake money, when we are trying to keep people healthy."

Phillip was a doctor of chiropractic with a degree in nutrition. Phillip saw himself as a "typical, conservative, redneck professional American," who became a chiropractor as an "alternative to taking prescription pharmaceuticals... I have people come all the time coming with a shopping bag full of pharmaceuticals that they are taking, and that can't be good." Phillip felt frustrated in his efforts to educate his medical colleagues on simple practices such as getting B12 testing and vitamin $\mathrm{D}$ testing alongside the traditional high sensitivity creactive protein and chem- 8 or chem- 14 blood chemistry profiles in the complete blood count laboratory diagnostics: "I find problems routinely on those tests, that certainly could be run by the patient's primary care physician or specialist, but they are just not." Phillip too attributed the lack of focus on prevention to: "lack of education [and] lack of felt need" by biomedical providers.

As a chiropractor, Phillip was aware that he didn't need referrals: "somebody may come off the street [with] back pain that may be due to a metastatic carcinoma," as he was licensed to diagnose and treat, and "evaluate whether they need to see the neurosurgeon or orthopedist." Moreover, he sought out neurologists and, "had [the] rare opportunity... to work within a multidisciplinary practice, to learn from, and see... [how] they worked, how they viewed things, and obviously, they from me." Phillip's position as a chiropractor allowed him to authorize diagnostic testing - a privilege many other CAM modalities are not accorded. At another level, Phillip sought to show scientific proof of the connection between nutrition and health. He described how he doesn't: "charge for that nutritional advice," but because his work involved long periods of "deep tissue work," he could "talk about things with patients that I consider important to their health." By requesting laboratory testing of vitamin-D levels, for example, Phillip could show his patients that: "there is nothing like getting back a blood test result, there it is in black and white... your vitamin D levels are down to around 18 instead of well above 30."

Phillip saw himself as setting an example for patient awareness, because: "who is going to listen to a doctor who is overweight, smoking cigarettes, and having a martini at lunch time, and telling you that you need to eat right and exercise, obviously." Phillip gave examples of thyroid diagnoses, where the typical allopathic approach is to receive synthetic T4, which, according to Phillip is problematic: "for one, that synthetic T4 has to be converted by the body into T3," as opposed to his approach to: "high potency thyroid or an iodine-high diet supplement," and then, "test them again in 2 to 3 months to see whether or not that has helped in TSH levels to come down." If they did not, Phillip sought to educate patients and refer them to "an endocrinologist in this town, who will prescribe bio-identical hormones." Phillip's discourse illustrates his ability to successfully network with biomedical colleagues such as neurosurgeons and endocrinologists. The prescription of Synthroid ${ }^{\circledR}$ [levothyroxine sodium tablets], according to Phillip exemplified: "the old way that hypothyroidism [was] treated...that, unfortunately... remains standard practice to this day, and there is a real danger to that approach." Phillip presented his approach as "based by sound science...coming from... a medical doctor, who just happens to practice outside the mainstream." Although he was critical of conventional medical education, Phillip saw his assumptions as aligning with the biomedical model of care: "pharmaceutical company interests have... influenced [medical education], to the extent that...medical doctors...only know prescribing pharmaceuticals... The art of medicine... sadly has taken a back seat, to just coming in, writing a script, and sending everyone out." Phillip too saw his CAM practice as part of conventional scientific realm and sought to broaden CAM as science by being a part of the prevention-diagnosis-treatment continuum.

Dick, who runs his own yoga practice, was introduced to yoga when he was in the Special Forces in the military, where, according to Dick, "they used it as a recovery sequence. They didn't teach it mindfully, but the physical practice made me feel better mentally, and a little bit physically." As he learned later, "they never called it yoga-it was called recovery sequence, but it was vinyasa, [that] is what we were doing, and it got us out of our head-out of the: 'I can't, I won't, the negative, or belowthe-line mentality," to make the mind-body connection: "and into the: 'I can do this'... the breath kind-of makes-everythingelse-happen, and it worked." Although Dick was skeptical about the unregulated nature of CAM, he was: "conflicted on whether to make it more mainstream...like, you need to have a college degree in science... like, even yoga, for example, that you don't need to have any real understanding of the body." However, certifications and licensing were part of the problem, as: "your degree is just a piece of paper... [certification programs] teach you how to pass the test. And then you get your license, and then, you have to figure out how to do the job" (Dick). Dick saw a need for more biomedical rigor in the training of practitioners in CAM modalities like yoga. For Dick, the problem lay also, in part, with: "why not earlier on make it more preventative...'Oh, now 
that you have the injury, we do yoga,' versus, 'maybe before you have an injury... 'hey, part of your wellness program is... yoga."” Thus, Dick advocated for a greater focus on CAM modalities (like yoga) being integrated at the preventive end of the healthcare continuum. Dick too aligned with biomedical providers who were his clients: "so it's a lot of give and take." On the one hand, Dick was "a sponge for knowledge in society"; on the other hand, he saw himself as a provider, "so I give [advice]: if I were in your shoes, this is what I would do," whose duty was to educate. Thus, Dick aligned with scientific assumptions of the biomedical system while contributing to expanding its understandings. At the same time he was aware of the limitations of CAM providers: "it's not in the scope of my practice to diagnose or implement certain things."

CAM practitioners' discourse represented their knowledge as analogic with allopathic discourse to legitimize their practice as science: "holistic practitioners don't use general drug therapy; they use, a lot of times, homeopathy and extreme nutrients and food" (Ana). Faith in personal beliefs was offered as equivalent to scientific validation: "my practice is my personal philosophy ... everything that we are here, is what I believe in, and I only work with people who are one with that" (Brianna). Holistic health was constituted through self-intent and emphasized self-management and responsibility in care: "I know this is what I want, and I am going to find a way to make it happen" (Brianna). Alexis equated her practice with science: "every cell, every molecule, is vibrating. And so, can I see energy work being powerful? Yes, I can. Because you are altering the energies around people that change."

At other times, CAM practitioners' discourse illustrated the tensions of being too closely aligned with the allopathic model. Alice felt essential oils were calming, but she "steered away from not [going] as far as integrating that into my practice, because...that came too close to medicine." CAM practitioners' discourse revealed the competing tensions characterizing credentialing and licensure among healthcare professions in medicine: "you really have to become a neurologist, to really study herbs, and $[\mathrm{k}]$ now what you are doing, because you could actually do harm if you are not careful" (Alice). Alice's discourse illuminated the sociocultural ambiguities surrounding holistic health: "my clients have...told me that 'I am so glad you're not into all [that] other stuff," asking her: "you are not trying to do something strange with me?' And [they] say, 'is it going to work?"' Ultimately, Alice clarified that she was: "just here to do massage, I am trained to work with your muscles, and relieve tension in the muscle, that's my focus." Alice's discourse reveals how she referenced her credibility in emphasizing her training, which did not equip her with the scientific knowledge for integrating herbs to benefit her clients. At the same time, her discourse reveals her self-imposed restriction in conforming with the sociocultural landscape (as referenced by her clients) to limit the scope of her practice.

The epistemologies of legitimization and identity worked to increase awareness of, align, or contest differences between ways of knowing. Practitioners portrayed their model of care as being aligned with the goals of science and sought to align with the preventive continuum of the allopathic model. Practitioners contested differences through highlighting their training or limiting their practice to align with normative sociocultural assumptions.

\section{Epistemologies of Sense and Intuition}

CAM providers' discourse employed epistemologies of sense and intuition to represent tensions between, and draw parallels with, the scientific foundations of allopathic practice to offer competing ways of validating evidence (Table 2). CAM providers justified their practice by using their body as evidence for evaluation, diagnosis, and treatment, describing care as intimately connected with abstract and spiritual experiences grasped through sense and intuition.

Ana described how her clients: "come for spiritual reasons, some people feel blocks... and they would literally sob and cry, and release those feelings of horrible guilt, and it was so cathartic." Ana, a Reiki practitioner, described how she used intuition to facilitate "deep relaxation, because it's the only way that our body can, and the mind can, heal...that's the physical level of how it works." Beyond the physical: "then there is an underlying spiritual level also, [that] can't be really explained, it can only be experienced" (Ana). Halen, a Bikram yoga instructor, explained how: "I don't know why... this one posture does this to your body, I have no idea." He described how, in his teachings, Bikram was "like, I just know that it works. I know from proof of people, I know from proof of myself." Halen took his teacher's experience of his own body as proof, and, in turn, communicated healing through yoga as being perceived through sense and intuition.

CAM practitioners employed analogies connecting abstract and tangible practices to describe sense and intuition. Brianna's analogy referenced routine physical actions to explain spiritual cleansing: "every day you take a shower, because our body has some specific functioning that makes us smell if we don't." Brianna explained the connection between the body and intuition: "people don't think about the issues that they [go] through, some of the issues are dirty too, and they hurt us, and... we just keep them inside, which is mentally, and then the trash can is full, and people don't have a practice to empty them." Brianna described healing in pragmatic terms as guiding patients to use sense and intuition to cleanse their bodies: "if were as good as we are with our shower... in emptying the emotional trash can, then that's healing."

Catherine worked as a communications security analyst with the federal government before starting her own Reiki practice: "When I have heart surgery, I have been able to Reiki myself prior to the surgery, and after the surgery...I am in less pain...my body heals quicker. It provides that universal life force energy." Catherine shared her experience providing Reiki at a medical center alongside oncologists and hematologists as evidence of its efficacy: "there has not been one regression.... and stats have... shown it to the medical directors there, [thus] where [they have] the oncology floor, to the infusion center...for patients getting [where they] are getting chemo, they receive Reiki." Yet, Catherine's discourse revealed a struggle with describing her practice as medicine: "It's working with the individual's energy field, and by looking at this as medicine in a way that's trying to help them. I guess I am struggling with the word medicine." 
When probed further, Catherine struggled: "to think of the right word to describe it, because... If not a medicine, it's an energy means... Medicine is what we box it into, because we don't know what else to call it." When asked why she was uncomfortable with using medicine to describe her work, Catherine noted: "I look at medicine as something you take, something you do, it's a medical process, but medicine to me is something that is not abstract."

CAM practitioners described the challenge of employing conventional evidence to describe the efficacy of sense and intuition: "There is a lot of anecdotal evidence, but not the double-blind study... that work I don't think has just really been done" (Harry, a chiropractor). Others described their skepticism in their own work:

acupuncture is very intangible... You are working on the body's energy system, and there is nothing to see other than the person's response to the treatment. So, even now... there are times that I am...not skeptical, but it is hard to not [be], that I am trying to convince anyone. (Charles, an acupuncturist)

Charles' discourse exemplifies how he struggled as a CAM provider to represent how he intuited his clients' recovery to justify his work for lack of tangible evidence.

Bob assessed holistic health as: "the lifestyle, a good sleep, and... how much work you are doing, nutrition, water, and excess sunlight...the condition of your relationships...the spiritual aspects." Likewise, Amy assessed holistic health as: "not just where you're aches and pains... it's really, how do you eat, what kind of exercises did you do, what kind of job did you have, how do you feel at the end of the day, how do you feel when you first wake up?" Karl, a chiropractor, described how he employed sense and intuition in his healing: "I'll have my own idea, I'll see the way they walk in, I'll see the way they sit, I'll see the way they stand up, and I have an idea before I even start doing anything [of] what's wrong with them."

The epistemologies of sense and intuition referenced how CAM providers employed sense and intuition to constitute holistic health through the experience of the provider's own and their patient's body. CAM practitioners justified their work through alignment with biomedicine in patient care at biomedical centers while also contesting biomedicine knowledge positions as being limited in their ability to go beyond narrowly defined criteria to demonstrate their efficacy (e.g., double-blind clinical trials).

\section{Epistemologies of Environment and Community}

CAM providers' discourse employed epistemologies of environment and community to represent tensions between, and draw parallels with allopathic practice to highlight the connection with the biological-sociocultural-epigenetic environment and the self (Table 2). The epistemologies of environment and community constituted holistic health as the balance between the biological-sociocultural-epigenetic environment.

Brianna described epigenetics as balance in the biological environment: "I could have been born with all th[ese] conditions, but if I take care of the environment of each cell of my body, I'm not going to have that illness." Ana highlighted the internal balance of: "the spiritual practice and the healing of myself every day, it's not a miracle... my metabolism has changed." Charles, an acupuncturist, described how this balance empowered patient agency: "I think a lot of the cancers... heart disease... a lot of the conditions that we say are autoimmune or genetic, are actually epigenetic and we have a huge ability to control them." Thus, CAM provider discourse of environment and community also highlighted the role of patient and provider agency in the manifestation and treatment of disease.

Dick emphasized the sociocultural environment characterizing CAM as: "unregulated... anytime someone says we're all natural, they're hiding something." Alice, a Christian massage therapist, highlighted the sociocultural context: "[it] all depends I think, on your culture, what you have been brought up with, and what you would use to treat something." Others looked at the social context of their clients, noting how, in:

Chinese medicine, the mind follows the body... So, if you have something going on with your lungs, you will probably...be sad... When I look at someone's toe, I'll be talking...I won't just be putting a needle in their toe... I'll be talking to them about... what they're eating, and... what they're drinking and what's happening at their house.... are they in a good environment, are they safe. (Carly, acupuncturist)

Carly felt her experience in Japan influenced the culture of her practice in the US. In Japan, when her daughter had a fever, she visited the community clinic, where: "the doctor was very angry with me," saying, "You should have been here two weeks ago when this was a small problem, but you've let it develop into something so big." Carly learned acupuncture from Chinese and Japanese doctors, but their culture of learning was different: "because where I learned, it was memorizing 20 things for everything... every acupuncture point, so it was all memory, memory, memory." There were cultural aspects to her practice. She practiced the Japanese approach, which is "even more comprehensive-with looking at Chinese medicine, Japanese, Korean. It's all one medicine," or "it's an understanding of the way chi moves in the body." Moreover, Carly described how the internal environment of the biological cell was connected with its external sociocultural environment:

A cell biologist is going to grow a cell. If it starts to fail, then don't look at the cell itself, look at the environment it's in. So, if you have a toxic environment, the cells are not going to [get better]... So, you don't think of that so much, but the people you live with, and the environment you live in, is critical to your health.

Carly's discourse illuminates the balance between the sociocultural context of her practice as well as the context of its training and the epigenetic context of the body.

For Madison, an aerial yoga instructor, balance in the connection between the biological and sociocultural environment and the individual's energy was important: "if you can transcend the flesh and connect to energy," according to Madison: "if someone can use their energy for healing for someone, just like a counselor in a room, she's calming her energy down to help." For Karl, an acupuncturist, lifestyle 
and exercise were important components in holistic healing "because that's mentally and physically...the way they deal with stress...the pain." At the same time, for Karl: "if you('re) coming to me with lower back, I'm going to focus on your lower back... I'm not going to [ask] what have you eaten since Monday, because... I don't want to get into that." Karl's discourse illustrates that although the sociocultural context was important to the treatment, he felt his qualifications precluded him from addressing those aspects in his treatment of the patient's condition. Max, a hypnotist, who obtained his certification from the Association for Research and Enlightenment at Virginia Beach, found the: "real challenge... is to integrate the messages and the perspective of the subconscious mind with the directions of the conscious mind...And, wellness is really developing a sense of integration between conscious and subconscious." Max defined hypnosis as "complementary but not exclusive" in aligning the physiological with the cognitive. For Max, the biological-sociocultural-epigenetic continuum could be grasped through the subconscious mind to address particular forms of health conditions.

CAM practitioners constructed disease as toxicity in describing the epistemologies of environment and community. Their discourse described the potential and limitations of their practice in achieving a balance between the environment (i.e., the biological or the sociocultural context), the practitioner, and the clients' biological and epigenetic factors. Max situated connections between the: "psychological, the spiritual, the biochemical, and structural elements of the person" during hypnosis by connecting with his clients': "belief system and [t]o work with particular client's mythology." Phillip described the provider-patient relationship as a "commitment to his patients', and his interest 'in doing... what that patient needs done." Catherine located knowledge as a balance between many pathways and communities: "coming from different societies and different cultures... there are so many natural ways of doing things."

CAM providers sought to align their work with biomedicine (e.g., psychotherapy or physical therapy), or contest differences by reconciling different cultural assumptions in learning (e.g., memorizing versus discussing) or by aligning their practice in a way that affirmed their clients' biological-socioculturalepigenetic environment to achieve health. In their discourse, practitioners emphasized their conceptualization of healing constituted as a balance between cellular, metabolic, and sociocultural processes and the self.

\section{DISCUSSION}

CAM provider epistemologies define holistic health through aligning themselves with the goals of science, conceptualizing and validating evidence, and as a biological-sociocultural-epigenetic relational praxis. CAM providers employ the epistemological foundations of legitimization and identity, sense and intuition, and environment and community to situate the meanings of holistic health within the normative discourse. The findings contribute to integrating CAM knowledge of holistic health in medical education to provide better patient care and by identifying tensions undergirding CAM providers' agency in establishing the efficacy of their practice, carving out a shared knowledge space, and distinguishing their professional identity.

The epistemologies engage with the challenges facing healthcare professionals in integrating CAM care during provider-patient interactions, self-management support, evidence-based research, and provider education (Jonas, 2001; Sharf and Vanderford, 2003). This examination illuminates how CAM providers center their knowledge to envisage an equitable and informed representation of their practice in medical and consumer education.

The epistemologies invite a reconsideration of biomedical and CAM provider positionality in conceptualizing IM and centering the practitioner's body and patient agency in the constitution of health. The CAM providers' discourse reveals the discomfort among clients and biomedical providers alike in affirming their practice as science or intangible outcomes as legitimate. Their appropriation of non-binary and nonsensory parameters deconstructs the experiential and relational boundaries of holistic health alongside the normative discourse of numerically accepted ranges, empirically assessed diagnoses, and objectively conceptualized outcomes. The CAM providers' discourse presents holistic health as arising from cultural and individual belief systems embedded in the axiological and ontological assumptions that support particular forms of their justification and validation within particular historical and sociocultural contexts. The increasing appropriation of CAM in the US healthcare landscape driven by the biomedical paradigm is removed from the sociocultural belief systems of their origin. In particular, the lack of an ontological framework for incorporating CAM content into standard allopathic education and viewing CAM as an aspect of cultural sensitivity have bedeviled IM in the U.S. (Nedrow et al., 2007). The epistemological pathways posit a framework of holistic health encompassing legitimacy and identity, sense, and intuition, and biological-socioculturalepigenetic relationality that provides an entryway to positioning CAM within the knowledge foundations of allopathic medicine. In doing so, they encompass the ontological and experientialrelational praxis to foreground health as a mutually constitutive, ongoing process of granting legitimacy to diverse sense-making ontologies of medicine and access to a whole body experience within a continuum of provider-patient meaning-making.

Conceptualizing an integrative model of care promises to bring greater sensitivity and awareness to the practice of medicine and health. The epistemologies suggest how CAM philosophies can be integrated in medical education through knowledge of the sociocultural and historical perspectives referenced by the epistemological framework of legitimacy and identity, sense and intuition, and environment and community to envisage deeper understandings of the whole body in medicine. The ontological praxis referenced by epistemologies of legitimization and identity emphasizes the alignment, bridging, or reconciliation of differences in aligning with science or the preventive end of the allopathic model. The axiological praxis referenced by epistemologies of sense and intuition aligns with and contests the biomedical knowledge positionality in 
diagnosis and treatment. The relational praxis referenced by the epistemologies of biological-sociocultural contexts integrates the self with its internal and external experiences in a healthcare relationship experienced as a whole body within an epigeneticsociocultural continuum.

The study findings underscore the importance of considering structural and cultural factors in healthcare (Dutta, 2007). CAM providers' discourse reveals their complex and contradictory positioning in the US as being simultaneously a product of the belief structures defining allopathic principles in the normative sociocultural discourse, yet in their practice, appropriating and aligning with a philosophically distinct model of care. Their discourse constructed the CAM identity as both appropriating competing ontological perspectives drawing from distinct belief and philosophical paradigms and as being constructed and enacted within a sociocultural healthcare landscape dominated by the biomedical model. In reconciling and aligning their approach with science, CAM providers sought to expand awareness of the foundations of their field and the parameters of their practice. CAM providers' discourse represented holistic health as responding to the normative allopathic dialogue (in expanding the preventive discourse or the evidentiary criterion) rather than representing the knowledge and practice of CAM as constituting their professional identity on its own terms. Thus, on the one hand, the findings contribute to the call for extending theoretical and pragmatic understandings of how practitioner discourse can inform balanced, knowledgeable, and skillful physician-patient communication, particularly in CAM-focused encounters or integrative settings (Ben-Arye et al., 2008). On the other hand, the findings highlight the need for deconstructing culturally situated understandings of health as they inform the knowledge and practice of integrative models of care in medical discourse.

As a small, qualitative study employing a purposive sampling design with a maximum variability criteria, the findings tap into the breadth of knowledge and experience in an in-depth manner, and sought to compare and contrast similarities and differences. However, the generalizability of the findings are limited as compared with probabilistic sampling methods that can control for bias in selection and for the potential influence of known or unknown confounders as in an quantitative study. Second, the findings can be extended through culture-centered approaches interrogating the structural, cultural, and social dimensions with agency in the construction of medicine as a field of knowledge and practice between the different models of care (e.g., Dutta, 2007).

Although national policies on integration of diverse medical models vary globally, the findings can contribute to informing CAM integration through supporting articulation of informed national policy, practitioner credentialing, and representation of CAM in consumer and patient communication (World Health Organization, 2004). The integration of holistic health practices that constitute a fundamental part of local belief systems with biomedical care has the potential to help with provision of healthcare in rural and developing world contexts in seminal ways (Flannery et al., 2006). For example, in India and China, where two whole systems approaches of Ayurveda and Traditional Chinese Medicine (TCM), informal ways for integrating these in patient care have a long-standing and vibrant tradition in many health domains. The findings can thus, help inform policy-makers in the US specifically, globally, and in developing countries in their articulation of formal processes integrating CAM and allopathic models of care.

\section{Practice Implications}

The epistemologies provide a framework to integrate CAM knowledge and evidence basis in allopathic medical education. In doing so, they address the call for an evaluation of CAM modalities' employed by patients by the physician to provide advice, monitor outcomes, evaluate current knowledge on indications and contraindications of that modality, and establish familiarity and an open dialogue with the patient's CAM therapist (Frenkel and Borkan, 2003). The study findings recommend a more fundamental approach to including CAM knowledge discourses in medical education and the epistemological foundations of basic medicine to envisage an integrative system and have important practice implications for CAM and biomedicine providers and IM generally.

\section{CAM Providers}

CAM provider communication inter-professionally with biomedical providers can enhance coordination of care through expanding normative definitions of health in comprehensive ways, such that different models of care are appreciated for their distinct strengths within their positionality. CAM providers' employment of their own body as an instrument of care and for validating evidence as situated within the context of the whole body can expand understandings of parameters for CAM in treating specific conditions and with particular modalities in their communication with clients.

\section{Biomedical Providers}

The findings suggest biomedical practitioners seeking to incorporate integrative techniques to engage their patients with a holistic and collaborative approach to healing to: (a) incorporate deeper understandings of healing as patientempowering phenomenon that can be cultivated from within the patient themselves by broadening understandings of science; (b) to acknowledge and incorporate spirituality and emotions in the healing process with their patients; and (c) to recognize their own bodies, nature, and lifestyles as tools in understanding their patients' lived contexts in constituting healthcare.

\section{Integrative Medicine}

The findings can help inform IM providers' meaning-making framework in patient communication, help the providers' as they attend to symptoms during the note-taking session, promote increasing awareness of the providers' own body in relationship with their patients' bodies and cultural environment, credentialing of CAM practitioner teaching within allopathic health professional institutions, and faculty development within existing allopathic health professional schools. 


\section{ETHICS STATEMENT}

This study was carried out in accordance with the recommendations of Human Subjects Research Committee, Salisbury University, with oral and recorded informed consent from all subjects. All subjects gave written informed consent in accordance with the Declaration of Helsinki. The protocol was approved by the Human Subjects Research Committee, Salisbury University.

\section{INFORMED CONSENT AND PATIENT DETAILS}

I confirm all patient/personal identifiers have been removed or disguised so the patient/person(s) described are not identifiable and cannot be identified through the details of the story.

\section{REFERENCES}

ACCAHC/OCCIM Task Force. CAM Educator Response to IM Curriculum and Values: Excerpt on Key Outcomes of the Delphi Survey Process. Retrieved from: https://pdfs.semanticscholar.org/72cd/ c7172967f87942a671 efcbca199505bc7997.pdf

Agarwal, V. (2017). Breaking boundaries: complementary and alternative medicine provider framing of preventive care. Qual. Health Res. 27, 1-12. doi: $10.1177 / 1049732317723891$

Agarwal, V. (2018). Taking care, bringing life: a post-structuralist feminist analysis of maternal discourses of mothers and Dais in India. Health Commun. 33, 423-432. doi: 10.1080/10410236.2016.1278492

Ahn, A. C., Tewari, M., Poon, C. S., and Phillips,. R. S. (2006). The limits of reductionism in medicine: Could systems biology offer an alternative? PLoS Med. 3:e208. doi: 10.1371/journal.pmed.0030208

Almeida, J. (2016). Complementary and alternative medicine's occupational closure in Portuguese healthcare: contradictions and challenges. Health (London) 20, 447-464. doi: 10.1177/1363459316660857

Bann, C. M., Sirois, F. M., and Walsh, E. G. (2010). Provider support in complementary and alternative medicine: exploring the role of patient empowerment. J. Altern. Complement. Med. 16, 745-752. doi: $10.1089 / \mathrm{acm} .2009 .0381$

Barrett, B., Marchand, L., Scheder, J., Plane, M. B., Maberry, R., Appelbaum, D. et al. (2003). Themes of holism, empowerment, access, and legitimacy define complementary, alternative, and integrative medicine in relation to conventional biomedicine. J. Altern. Complement. Med. 9, 937-947. doi: $10.1089 / 107555303771952271$

Ben-Arye, E., Frenkel, M., Klein, A., and Scharf, M. (2008). Attitudes toward integration of complementary and alternative medicine in primary care: perspectives of patients, physicians, and complementary practitioners. Patient Educ. Couns. 70, 395-402. doi: 10.1016/j.pec.2007.11.019

Benjamin, P. J., Phillips, R., Warren, D., Salveson, C., Hammerschlag, R., Snider, P. et al. (2007). Response to a proposal for an integrative medicine curriculum. J. Altern. Complement. Med. 13, 1021 11033. doi: 10.1089/acm.2006.6388

Broom, A., and Tovey, P. (2008). The role of the Internet in cancer patients' engagement with complementary and alternative treatments. Health (London) 12, 139-155. doi: 10.1177/1363459307086841

Caspi, O., Sechrest, L., Pitluk, H. C., Marshall, C. L., Bell, I. R., and Nichter, M. (2003). On the definition of complementary, alternative, and integrative medicine: Societal mega stereotypes vs. the patients' perspectives. Altern. Ther. Health Med. 9, 58-62.

Caulfield, T., and DeBow, S. (2005). A systematic review of how homeopathy is represented in conventional and CAM peer reviewed journals. BMC Complement. Altern. Med. 5:12. doi: 10.1186/1472-6882-5-12

\section{AUTHOR CONTRIBUTIONS}

The author confirms being the sole contributor of this work and approved it for publication.

\section{FUNDING}

This research was funded in part by the Faculty Research Grant, Fulton School of Liberal Arts, Salisbury University, Salisbury, Maryland, USA.

\section{SUPPLEMENTARY MATERIAL}

The Supplementary Material for this article can be found online at: https://www.frontiersin.org/articles/10.3389/fcomm. 2018.00015/full\#supplementary-material

Chatwin, J. (2012). Damning with faint praise: how homoeopaths talk about conventional medicine with their patients. Commun. Med. 9, 191-201. doi: 10.1558/cam.v9i3.191

Cochrane, S., and Possamai-Inesedy, A. (2013). Looking outside the square: the use of qualitative methods within complementary and alternative medicine: the movement toward rigor. Complement. Ther. Med. 21, 73-76. doi: 10.1016/j.ctim.2012.11.002

Coelho, H. F., Pittler, M. H., and Ernst, E. (2007). An investigation of the contents of complementary and alternative journals. Altern. Ther. Health Med. 13, 40-44.

Cresswell, J. W., and Plano Clark, V. L. (2011). Designing and Conducting Mixed Method Research, 2nd Edn. Thousand Oaks, CA: Sage.

Dutta, M. J. (2007). Communication about culture and health: theorizing culturecentered and cultural sensitivity approaches. Commun. Theory 17, 304-328. doi: 10.1111/j.1468-2885.2007.00297.x

Fairclough, N. (1995). Critical Discourse Analysis: The Critical Study of Language. New York, NY: Longman.

Fairclough, N., and Wodak, R. (1997). "Critical discourse analysis," in Discourse as Social Interaction, ed T. van Dijk (London: Sage), 258-284.

Flannery, M. A., Love, M. M., Pearce, K. A., Luan, J. J., and Elder, W. G. (2006). Communication about complementary and alternative medicine: perspectives of primary care physicians. Altern. Ther. Health Med. 12, 56-63.

Foote-Ardah, C. E. (2004). Sociocultural barriers to the use of complementary and alternative medicine for HIV. Qual. Health Res. 14, 593-611. doi: $10.1177 / 1049732304263639$

Foucault, M. (1972). The Archaeology of Knowledge: And the Discourse on Language. New York, NY: Tavistock Publications Limited.

Frenkel, M. A., and Borkan, J. M. (2003). An approach for integrating complementary-alternative medicine into primary care. Fam. Pract. 20, 324-332. doi: 10.1093/fampra/cmg315

Giordano, J., Boatwright, D., Stapleton, S., and Huff, L. (2002). Blending the boundaries: steps toward an integration of complementary and alternative medicine into mainstream practice. J. Altern. Complement. Med. 8, 897-906. doi: 10.1089/10755530260511892

Helyer, L. K., Chin, S., Chui, B. K., Fitzgerald, B., Verma, S., Rakovitch, E., et al. (2006). The use of complementary and alternative medicine among patients with locally advanced breast cancer-a descriptive study. BMC Cancer 6:39. doi: 10.1186/1471-2407-6-39

Hirschkorn, K. A. (2006). Exclusive versus everyday forms of professional knowledge: legitimacy claims in conventional and alternative medicine. Sociol. Health Illness 28, 533-557. doi: 10.1111/j.1467-9566.2006.00506.x

Ho, E. Y., Tran, H., and Chesla, C. A. (2015). Assessing the cultural in culturally sensitive printed patient-education materials for Chinese Americans with type 2 diabetes. Health Commun. 30, 39-49. doi: 10.1080/10410236.2013.835216 
Hollenberg, D. (2006). Uncharted ground: patterns of professional interaction among complementary/alternative and biomedical providers in integrative healthcare settings. Soc. Sci. Med. 62, 731-744. doi: 10.1016/j.socscimed.2005.06.030

Hsiao, A. F., Ryan, G. W., Hays, R. D., Coulter, I. D., Anderson, R. M., and Wenger, N. S. (2006). Variations in provider conceptions of integrative medicine. Soc. Sci. Med. 62, 2973-2987. doi: 10.1016/j.socscimed.2005. 11.056

Hsieh, E., Bruscella, J., Zannin, A., and Kramer, E. M. (2016). "It's not like you need to live 10 or 20 years": challenges to patient-centered care in gynecologic-oncologist-patient interactions. Qual. Health Res. 26, 1191-1202. doi: $10.1177 / 1049732315589095$

National Center for Complementary and Integrative Health (2017a). NCCIH's Funding Opportunities and Research Focus. Available online at: https://nccih. nih.gov/about/researchfocus

National Center for Complementary and Integrative Health (2017b). The Use of Complementary and Alternative Medicine in the United States: Cost data. Available online at: https://nccih.nih.gov/news/camstats/costs/costdatafs.htm

Jagtenberg, T., Evans, S., Grant, A., Howden, I., Lewis, M., and Singer, J. (2006). Evidence based medicine and naturopathy. J. Altern. Complement. Med. 12, 323-328. doi: 10.1089/acm.2006.12.323

Jain, N., and Astin, J. A. (2001). Barriers to acceptance: an exploratory study of complementary/alternative medicine disuse. J. Altern. Complement. Med. 7, 689-696. doi: 10.1089/10755530152755243

Jonas, W. B. (2001). Advising patients on the use of complementary and alternative medicine. Appl. Psychophysiol. Biofeedback 3, 205-214. doi: 10.1023/A:1011398120476

Jong, M. C., van de Vijver, L., Busch, M., Fristma, J., and Seldenrijk, R. (2012). Integration of complementary and alternative medicine in primary care: what do patients want? Patient Educ. Couns. 89, 417-422. doi: 10.1016/j.pec.2012.08.013

Kantor, M. (2009). The role of rigorous scientific evaluation in the use and practice of complementary and alternative medicine. J. Am. Coll. Radiol. 6, 254-262. doi: 10.1016/j.jacr.2008.09.012

Mertz, M. (2007). Complementary and alternative medicine: the challenges of ethical justification. Med. Health Care Philos. 10, 329-245. doi: 10.1007/s11019-007-9050-x

Miles, M. B., and Huberman, A. M. (1994). Qualitative Data Analysis: An Expanded Sourcebook, 2nd Edn. Thousand Oaks, CA: Sage.

Mizrachi, N., and Shuval, J. T., and Gross, S. (2005). Boundary at work: alternative medicine in biomedical settings. Sociol. Health Illn. 27, 20-43. doi: $10.1111 / j .1467-9566.2005 .00430 . x$

Nahin, R. L., Barnes, P. M., Stussman, B. J., and Bloom, B. (2009). Costs of Complementary and Alternative Medicine (CAM) and Frequency of Visits to CAM Practitioners: United States, 2007. National Health Statistics Reports; No 18. Hyattsville, MD: National Center for Health Statistics.

Nedrow, A. R., Heiktemper, M., Frenkel, M., Mann, D., Wayne, P., and Hughes, E. (2007). Collaborations between allopathic and complementary and alternative medicine health professionals: four initiatives. Acad. Med. 82, 962-966. doi: 10.1097/ACM.0b013e31814a4e2c

Ooi, S. L., Rae, J., and Pak, S. C. (2016). Implementation of evidence-based practice: a naturopath perspective. Complement. Ther. Clin. Pract. 22, 24-28. doi: 10.1016/j.ctcp.2015.11.004

Patton, M. Q. (2002). Qualitative Research and Evaluation Methods: Integrating Theory and Practice. Thousand Oaks, CA: Sage.

Ramadurai, V., Sharf, B. F., and Ramasubramanian, S. (2016). Roads less traveled: finding a path to using complementary and alternative medicine. Qual. Health Res. 26, 1216-1228. doi: 10.1177/1049732315582009
Roth, E. G., Girling, L. M., Chard, S., Wallace, B. H., and Eckert, J. K. (2017). Diabetes and the motivated patient: understanding perlocutionary effect in health communication. Health Commun. 32, 502-508. doi: $10.1080 / 10410236.2016 .1140270$

Schreiber, L. (2005). The importance of precision in language: communication research and (so called) alternative medicine. Health Commun. 17, 173-190. doi: $10.1207 /$ s15327027hc1702_4

Scott, A. M., and Caughlin, J. P. (2015). Communication nonaccommodation in family conversations about end-of-life health decisions. Health Commun. 30, 144-153. doi: $10.1080 / 10410236.2014 .974128$

Sharf, B., Geist Martin P., Cosgriff-Hernández, K. K., and Moore, J. (2012). Trailblazing healthcare: institutionalizing and integrating complementary medicine. Patient Educ. Couns. 89, 434-438. doi: 10.1016/j.pec.2012.03.006

Sharf, B., and Vanderford, M. L. (2003). "Illness narratives and the social construction of health," in Handbook of Health Communication, eds T. L. Thompson, A. M. Dorsey, K. I. Miller, and R. Parrott (Mahwah, NJ: Lawrence Erlbaum), 9-34.

Shelley, B. M., Sussman, A. L., Williams, R. L., Segal, A. R., and Crabtree, B. F. (2009). "They don't ask me so I don't tell them": patient-clinician communication about traditional, complementary, and alternative medicine. Ann. Fam. Med. 7, 139-147. doi: 10.1370/afm.947

Strauss, A. L., and Corbin, J. M. (1998). Basics of Qualitative Research: Techniques and Procedures for Developing Grounded Theory. Thousand Oaks, CA: Sage.

Tilburt, J. C., and Miller, F. G. (2007). Responding to medical pluralism in practice: a principled ethical approach. J. Am. Board Fam. Med. 20, 489-494. doi: 10.3122/jabfm.2007.05.060205

Tracy, S. J. (2013). Qualitative Research Methods: Collecting Evidence, Crafting Analysis, Communicating Impact. Malden, MA: Wiley-Blackwell.

Verhoef, M. J., Lewith, G., Ritenbaugh, C., Boon, H., Fleishman, S., and Leis, A. (2005). Complementary and alternative medicine whole systems research: beyond identification of inadequacies of the RCT. Complement. Ther. Med. 13, 206-212. doi: 10.1016/j.ctim.2005.05.001

Wanchai, A., Armer, J. M., and Stewart, B. R. (2010). Complementary and alternative medicine use among women with breast cancer: a systematic review. Clin. J. Oncol. Nurs. 14, E45-55. doi: 10.1188/10.CJON.E45-E55

Willard, B. E. (2005). Feminist interventions in biomedical discourse: an analysis of the rhetoric of integrative medicine. Womens Stud. Commun. 28, 115-148. doi: $10.1080 / 07491409.2005 .10162486$

World Health Organization (2004). WHO Guidelines on Developing Consumer Information on Proper Use of Traditional, Complementary, and Alternative Medicine. Available online at: http://apps.who.int/medicinedocs/pdf/s5525e/ s5525e.pdf

Yang, L., Sibbritt, D., and Adams, J. (2017). A critical review of complementary and alternative medicine use among people with arthritis: a focus upon prevalence, cost, user profiles, motivation, decision-making, perceived benefits, and communication. Rheumatol. Int. 37, 337-351. doi: 10.1007/s00296-016$3616-y$

Conflict of Interest Statement: The author declares that the research was conducted in the absence of any commercial or financial relationships that could be construed as a potential conflict of interest.

Copyright (c) 2018 Agarwal. This is an open-access article distributed under the terms of the Creative Commons Attribution License (CC BY). The use, distribution or reproduction in other forums is permitted, provided the original author(s) and the copyright owner are credited and that the original publication in this journal is cited, in accordance with accepted academic practice. No use, distribution or reproduction is permitted which does not comply with these terms. 